Article

\title{
Increased Plasma Concentrations of Vitamin D Metabolites and Vitamin D Binding Protein in Women Using Hormonal Contraceptives: A Cross-Sectional Study
}

\author{
Ulla K. Møller ${ }^{1}{ }^{*}$, Susanna við Streym ${ }^{1}$, Lars T. Jensen ${ }^{2}$, Leif Mosekilde ${ }^{1}$, Inez Schoenmakers ${ }^{3}$, \\ Shailja Nigdikar ${ }^{3}$ and Lars Rejnmark ${ }^{1}$
}

1 Department of Endocrinology and Internal Medicine, THG, Aarhus University Hospital, Tage Hansens Gade 2, DK, Aarhus 8000, Denmark;

E-Mails: susanna.vid.streym@gmail.com (S.S.); leif.mosekilde@gmail.com (L.M.); rejnmark@post6.tele.dk (L.R.)

2 Department of Clinical Physiology, Glostrup University Hospital, Copenhagen DK-2900, Denmark; E-Mail: lars.thorbjoern.jensen@regionh.dk

3 MRC Human Nutrition Research, Cambridge CB1 9NL, UK;

E-Mails: inez.schoenmakers@mrc-hnr.cam.ac.uk (I.S.); shailja.nigdikar@mrc-hnr.cam.ac.uk (S.N.)

* Author to whom correspondence should be addressed; E-Mail: kristine.moller@ki.au.dk; Tel.: +45-78-45-21-25; Fax: +45-78-45-21-94.

Received: 19 July 2013; in revised form: 24 August 2013 / Accepted: 26 August 2013 / Published: 5 September 2013

Abstract: Use of hormonal contraceptives (HC) may influence total plasma concentrations of vitamin D metabolites. A likely cause is an increased synthesis of vitamin D binding protein (VDBP). Discrepant results are reported on whether the use of HC affects free concentrations of vitamin D metabolites. Aim: In a cross-sectional study, plasma concentrations of vitamin D metabolites, VDBP, and the calculated free vitamin D index in users and non-users of HC were compared and markers of calcium and bone metabolism investigated. Results: 75 Caucasian women aged 25-35 years were included during winter season. Compared with non-users $(n=23)$, users of HC $(n=52)$ had significantly higher plasma concentrations of 25-hydroxyvitamin D (25OHD) (median 84 interquartile range: [67-111] vs. 70 [47-83] nmol/L, $p=0.01)$, 1,25-dihydroxyvitamin $\mathrm{D}\left(1,25(\mathrm{OH})_{2} \mathrm{D}\right)$ (198 [163-241] vs. 158 [123-183] pmol/L, $p=0.01)$ and VDBP (358 [260-432] vs. $271[179-302] \mu \mathrm{g} / \mathrm{mL}, p<0.001)$. However, the calculated free indices (FI-25OHD and FI-1,25(OH $\left.)_{2} \mathrm{D}\right)$ were not significantly different between groups $(p>0.10)$. There were no significant differences in indices of calcium homeostasis (plasma concentrations of 
calcium, parathyroid hormone, and calcitonin, $p>0.21$ ) or bone metabolism (plasma bone specific alkaline phosphatase, osteocalcin, and urinary NTX/creatinine ratio) between groups. In conclusion: Use of HC is associated with $13 \%-25 \%$ higher concentrations of total vitamin D metabolites and VDBP. This however is not reflected in indices of calcium or bone metabolism. Use of HC should be considered in the interpretation of plasma concentrations vitamin D metabolites.

Keywords: hormonal contraceptives; 25hydroxyvitamin D; 1,25-dihydroxyvitamin D; vitamin D binding protein; parathyroid hormone; calcitonin; bone turnover; bone mineral density

\section{Introduction}

Vitamin D (calciferol) is obtained from endogenous synthesis in the skin in response to solar UV-B radiation and intake from the diet and supplements [1,2]. Once in the circulation, calciferol is converted to 25-hydroxyvitamin D (25OHD) in the liver and, subsequently, to its circulating biologically active form 1,25-dihydroxyvitamin $\mathrm{D}\left(1,25(\mathrm{OH})_{2} \mathrm{D}\right)$ in the kidney [3]. This conversion may also occur in other tissues for auto- or paracrine actions [4]. It has been estimated that $85 \%$ to $90 \%$ of $25 \mathrm{OHD}$ and $1,25(\mathrm{OH})_{2} \mathrm{D}$ is bound to vitamin $\mathrm{D}$ binding protein (VDBP) [5], $10 \%$ to $15 \%$ to albumin, whereas only a very small fraction $(<0.1 \%)$ circulates in its free form $[5,6]$. VDBP binding protects vitamin D metabolites from hydroxylase-mediated catabolism, affects their cellular uptake, and modulates their biological activity $[5,6]$.

Total plasma concentrations of $25 \mathrm{OHD}$ are considered an indicator of vitamin D status due to its long plasma half-life (approximately 15-35 days) and lack of hormonal control of the hepatic 25-hydroxylase [3].

Vitamin D is known to affect several health outcomes. Classically, low vitamin D concentrations are known to be associated with an increased risk of myopathy, rickets or osteomalacia, and low bone mineral density and fracture. In a number of recent studies, an impaired vitamin D status has also been associated with various adverse non-skeletal health outcomes such as an increased risk of malignancies or cardiovascular diseases [1].

Plasma 25OHD concentrations are influenced by many factors. In addition to variations in UVB-exposure and dietary intake, 25OHD concentrations are influenced by several host factors such as age, adiposity [2,7,8], ethnicity, and skin tone as well as certain genotypes [8,9], and plasma VDBP concentrations [5].

Pregnancy is known to be associated with an increase in VDBP through its oestrogen mediated increase in synthesis [10,11]. Plasma concentrations of 25OHD are reported to be unaltered and $1,25(\mathrm{OH})_{2} \mathrm{D}$ to be elevated compared to non-pregnant women [12-14]. The use of hormonal contraceptives (HC) may also affect 25OHD concentrations and metabolism due to their oestrogenic components. The limited data on the effects of $\mathrm{HC}$ on $25 \mathrm{OHD}$ concentrations report no change or an increase in total 25OHD [9,12,15-17], whereas most studies consistently report an increase in levels of $1,25(\mathrm{OH})_{2} \mathrm{D}$ and VDBP $[10,15,18-20]$. 
These data suggest that $\mathrm{HC}$ may cause differential effects on $25 \mathrm{OHD}$ and $1,25(\mathrm{OH})_{2} \mathrm{D}$; the free $25 \mathrm{OHD}$ index (the molar ratio of 25OHD- to VDBP-concentrations) may be decreased due to an absence of a parallel increase in VDBP and $25 \mathrm{OHD}$, whereas the free index of $1,25(\mathrm{OH})_{2} \mathrm{D}$ may remain unchanged.

In order to study the possible effects of $\mathrm{HC}$, we compared plasma concentrations of 25OHD, $1,25(\mathrm{OH})_{2} \mathrm{D}$, VDBP, and the calculated free vitamin D index in users and non-users of HC. In addition, we assessed possible impacts of $\mathrm{HC}$ on calcium homeostasis and bone metabolism.

\section{Subjects and Methods}

This paper reports a secondary analysis of the effects of $\mathrm{HC}$ on vitamin D metabolism in a subset of women participating in a population based controlled cohort study, using cross-sectional data obtained at baseline. The design of the study has previously been reported in detail [12,21]. In brief, we included 153 healthy Caucasian women, aged 25-35 years, trying to conceive, and 75 age-matched women not planning a pregnancy for the next 21 months. All women were recruited by direct mailing of 11,175 randomly selected women from a population of 21,317 women aged 25-35 years living in the community of Aarhus, Denmark. We obtained names and addresses from the Danish Civil Registration System. A total of 561 wished to participate, from which 333 were excluded as based on predefined exclusion criteria (Pregnant or breastfeeding at the start of the study $(n=85)$, known infertility $(n=46)$, miscarriage within last 6 months $(n=3)$, withdrawal or moved residence $(n=84)$, age, illness, foreign origin $(n=25)$, or responded after closure of recruitment $(n=90))$. Analyses reported in this paper only include data obtained in the group of women $(n=75)$ not planning a pregnancy, of which 52 were using hormonal contraception (including oral, subdermal contraceptive implant, or hormonal spiral methods). They were all included between October 2006 and April 2007. The study was performed according to The Helsinki Declaration II. The study was notified to the Danish Data Protection Agency (\#2004-41-4737) and approved by the Regional Scientific Ethical Committee of Aarhus County (\#20040186).

\subsection{Measurements}

Standing height and body weight were measured (Seca, Sa-med, Kvistgaard, Denmark) wearing indoor clothing. Incident diseases and the use of drugs were recorded. Participants were asked to fill in a questionnaire on medical conditions, smoking habits, and dietary intake of calcium as well as use of calcium and vitamin D containing supplements. Dietary intake of calcium was assessed as previously described [22] and total calcium intake was calculated as dietary intake plus intake from supplements.

\subsection{Biochemistry}

A non-fasting blood sample was drawn between 8 a.m. and 2 p.m. according to standardized procedures and centrifuged at $4{ }^{\circ} \mathrm{C}$ with a relative centrifugal force of $2500 \mathrm{~g}$ for $10 \mathrm{~min}$. Plasma was separated and stored at $-80{ }^{\circ} \mathrm{C}$ until analyzed. Urine and plasma samples were assessed in batches, i.e., all samples from each participant were analyzed in the same run, except for analysis of calcium, creatinine, and phosphate, which were analyzed within two hours after collection. A second void 
morning urine sample was collected at home. Urine samples were collected under fasting conditions or before any consumption of calcium rich foods. Plasma 25-hydroxyvitamin D (25OHD) concentrations were measured by isotope dilution liquid chromatography-tandem mass spectrometry (LC-MS/MS) by a method adapted from Maunsell et al. [23,24]. The method separately quantifies $25 \mathrm{OHD}_{2}$ and total $25 \mathrm{OHD}_{3}$ (including the 3 -epimer). The total $25 \mathrm{OHD}$ concentration was calculated and used for further analyses. Calibrators traceable to NIST SRM 972 (Chromsystems, DE) were used. The inter-assay CV was $<10 \%$, at plasma concentrations of $23.4 \mathrm{nmol} / \mathrm{L}\left(25 \mathrm{OHD}_{2}\right)$ and $24.8 \mathrm{nmol} / \mathrm{L}\left(25 \mathrm{OHD}_{3}\right)$. We determined plasma 1,25-dihydroxyvitamin $\mathrm{D}\left(1,25(\mathrm{OH})_{2} \mathrm{D}\right)$ concentrations by a radioimmunoassay (Gamma-B 1,25-Dihydroxy Vitamin D, Immunodiagnostic Systems (IDS) Ltd., Boldon, England). The inter- and intra-assay CV was $9.0 \%$ and $8.0 \%$, respectively, at $220 \mathrm{pmol} / \mathrm{L}$.

Vitamin D binding protein concentration was determined by ELISA (R \& D Systems, Abingdon, $\mathrm{UK}$ ) with both an inter- and intra-assay $\mathrm{CV}<6 \%$. Assay performance was monitored using kit and in-house controls and under strict standardization according to ISO 9001:2000.

The free fraction of $25 \mathrm{OHD}$ and $1,25(\mathrm{OH})_{2} \mathrm{D}$ were calculated as the free 25OHD index (FI-25OHD) and the free $1,25(\mathrm{OH})_{2} \mathrm{D}$ index $\left(\mathrm{FI}-1,25(\mathrm{OH})_{2} \mathrm{D}\right)$ using the molar ratio of $25 \mathrm{OHD}$ and $1,25(\mathrm{OH})_{2} \mathrm{D}$ to VDBP [11].

We determined plasma and urinary concentrations of calcium and creatinine ( $\mathrm{Cr}$ ) by standard laboratory methods and calculated the albumin adjusted calcium concentration according to the formula: plasma calcium, adjusted $[\mathrm{mmol} / \mathrm{L}]=$ plasma calcium, total $[\mathrm{mmol} / \mathrm{L}]+0.00086 \times(650$-plasma albumin $\mu \mathrm{mol} / \mathrm{L}$ ) [22].

Calcitonin was measured by a radioimmunoassay as described by Schifter [25]. The plasma concentrations of intact parathyroid hormone (PTH) and osteocalcin were measured with electro-chemiluminescence immunoassays using an automated instrument (Cobas 601e, Roche Diagnostics, GmbH, Mannheim, Germany). We measured plasma bone specific alkaline phosphatase concentrations by an immunoassay (METRA BAP EIA kit, Quidel Corporation, San Diego, CA, USA). The renal excretion of cross-linked $N$-terminal telopeptide of type 1 collagen (NTx) was quantified by ELISA using an automated instrument (Vitros ECI, Ortho Clinical Diagnostics, Amersham, UK). Results were expressed relative to creatinine $(\mathrm{Cr})$ excretion $(\mathrm{NTx} / \mathrm{Cr})$, as nmol of bone collagen equivalents (nMmol BCE) per mmol of creatinine. The $\mathrm{CV}$ was $9.6 \%$ at $41.5 \mathrm{nmol}$ BCE/mmol Cr.

We measured bone mineral density (BMD) of the whole body, the lumbar spine, and total hip. Total body fat and lean mass were measured. All DXA scans were performed using a Hologic Discovery scanner (Hologic, Waltham, MA, USA). We assessed long-term stability through daily scans of an anthropometrical phantom. Precision error for BMD was $1 \%$ at the lumbar spine and $2 \%$ at the total hip.

\subsection{Statistics}

The majority of the data were non-normally distributed, therefore descriptive statistics are reported as medians with the 25 and 75-percentile (p25; p75), unless stated otherwise. We explored the differences between groups using chi-square tests for categorical variables and a Mann-Whitney $U$-test for continuous variables. Spearman's rho correlation was used to calculate the magnitude and direction of the correlations between measured variables. 
Vitamin D status was described according to plasma 25OHD concentrations categorized into three groups: $25 \mathrm{OHD}<50 \mathrm{nmol} / \mathrm{L} ; 25 \mathrm{OHD}$ between 50.1 and $75 \mathrm{nmol} / \mathrm{L}, 25 \mathrm{OHD}>75.1 \mathrm{nmol} / \mathrm{L}$ [26].

All statistical analyses were performed using the Statistical Package for Social Sciences (SPSS 17, Chicago, IL, USA) for Windows. $P$-values below 0.05 were considered statistically significant.

\section{Results}

Table 1 shows characteristics of the 75 included women. Anthropometric-, diet-, and lifestyle-characteristics did not differ between women using hormonal contraceptives (HC) $(n=52)$ and non-users $(n=23)$, except that daily calcium intake was slightly higher in users- compared with non-users of $\mathrm{HC}(p=0.02)$.

Table 1. Characteristic of the 75 studied women stratified by use of hormonal contraceptives. Median with interquartile (p25; p75) ranges unless otherwise indicated.

\begin{tabular}{lllll}
\hline All, $\boldsymbol{n}=\mathbf{7 5}$ & $\begin{array}{l}\text { Users of } \\
\text { hormonal } \\
\text { contraceptive } \\
(\boldsymbol{n}=\mathbf{5 2})\end{array}$ & $\begin{array}{l}\text { Non-users of } \\
\text { hormonal } \\
\text { contraceptives } \\
(\boldsymbol{n}=\mathbf{2 3})\end{array}$ & $\boldsymbol{p ~ v a l u e ~}^{\mathbf{1}}$ \\
\hline Age, mean & $29(27 ; 32)$ & $29(27 ; 32)$ & $29(26 ; 33)$ & 0.81 \\
Weight, kg & $67(60 ; 77)$ & $69(63 ; 77)$ & $63(57 ; 80)$ & 0.12 \\
Height, cm & $168(163 ; 172)$ & $167(162 ; 172)$ & $169(163 ; 172)$ & 0.61 \\
BMI & $24(22 ; 27)$ & $25(23 ; 27)$ & $23(20 ; 27)$ & 0.12 \\
$\begin{array}{l}\text { Total calcium intake, mg/day } \\
\text { Use of vitamin D }\end{array}$ & $800(660 ; 975)$ & $850(700 ; 1000)$ & $700(500 ; 853)$ & 0.02 \\
supplements, $n(\%)$ & $24(32)$ & $17(33)$ & $7(30)$ & 1.00 \\
Vitamin D intake from & $5(5 ; 9)$ & $5(5 ; 10)$ & $5(5 ; 5)$ & \\
supplements $(\mu \mathrm{g} /$ day $)$ & $11(15)$ & $7(14)$ & $4(17)$ & 0.71 \\
Smoking, $n(\%)$ & 1 Independent-Samples Mann-Whitney U Test.
\end{tabular}

Of the $52 \mathrm{HC}$ users, 44 used oral HC, six used intrauterine hormonal device, one used sub-dermal contraceptive implant, and one used a vaginal ring. No differences in biochemical markers were seen between the 44 using oral $\mathrm{HC}$ and the six using intrauterine hormonal device (data not shown).

Physical activity, time spend outdoor, and the time of the day for blood sampling did not differ between the HC users and no-users of $\mathrm{HC}$ (data not shown). The number of women with a BMI above 25 was not different between users- and non-HC users. BMD at whole body, lumbar spine, and total hip, as well as fat and lean mass did not differ between the HC users and no-users of HC (data not shown). However, given the sample size of 23 non-HC users and 52 users our statistical power to detect a $5 \%$ difference between groups in lumbar spine BMD $(2 \alpha=0.05$ and $\beta=0.20)$ was only approximately $60 \%$.

When all data were pooled, the plasma concentrations of $25 \mathrm{OHD}$ was significantly and positively correlated with VDBP $\left(r_{\mathrm{s}}=0.26, p=0.03\right)$ (Figure $\left.1 \mathrm{~A}\right)$ and further with $1,25(\mathrm{OH})_{2} \mathrm{D}\left(r_{\mathrm{s}}=0.43\right.$, $p<0.01)$. 
Figure 1. (A) Scatter plot of linear relations between plasma 25OHD and VDBP in 75 healthy Caucasian women stratified by use of hormonal contraceptives; (B) Scatter plot of linear relations between plasma $1,25 \mathrm{OH}_{2} \mathrm{D}$ and VDBP in 75 healthy Caucasian women stratified by use of hormonal contraceptives.

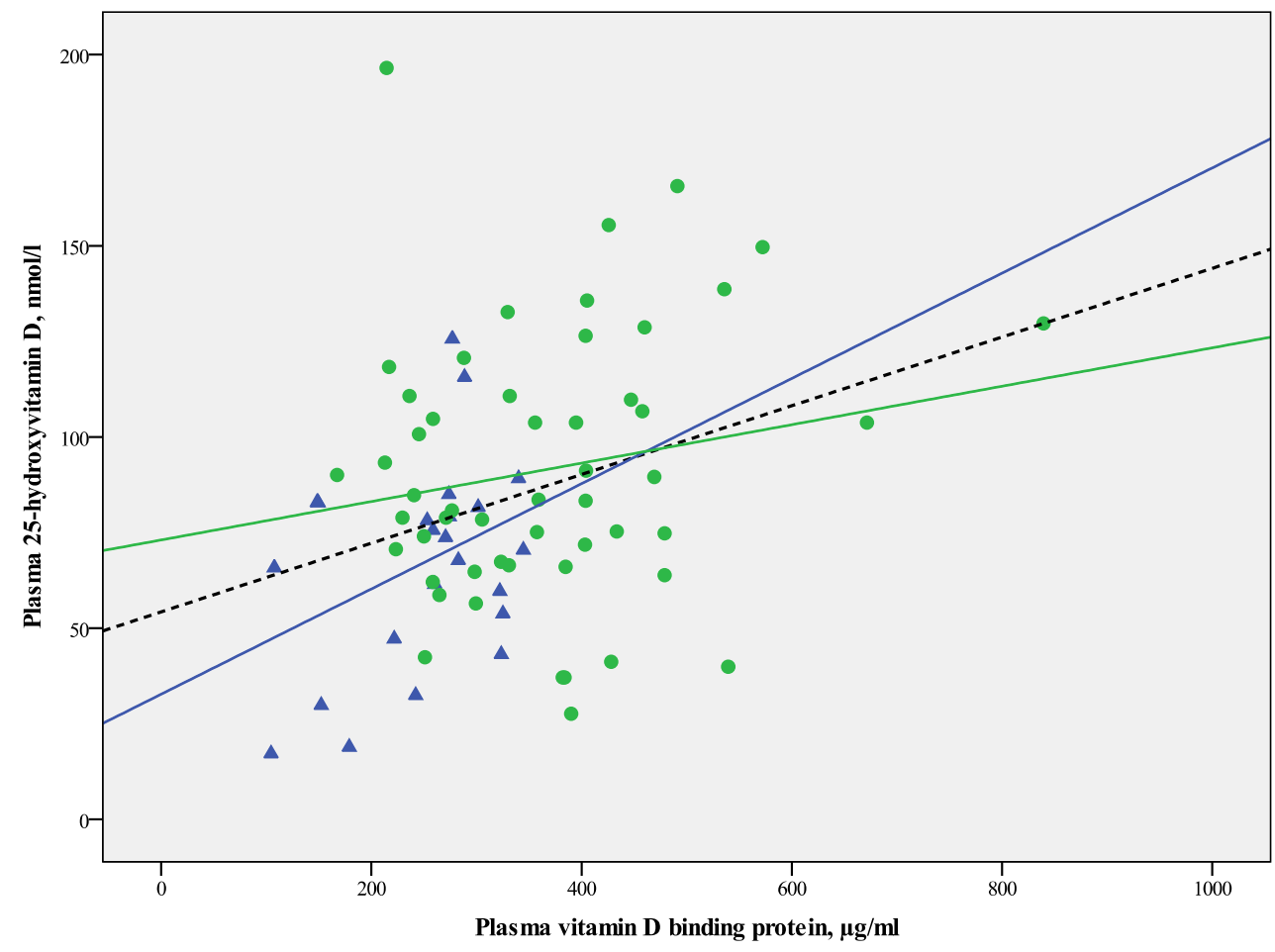

Hormonal contraceptive use

Non hormonal contraceptive users

Hormonal contraceptive users

Non hormonal contraceptive users

Hormonal contraceptive users

The group as one

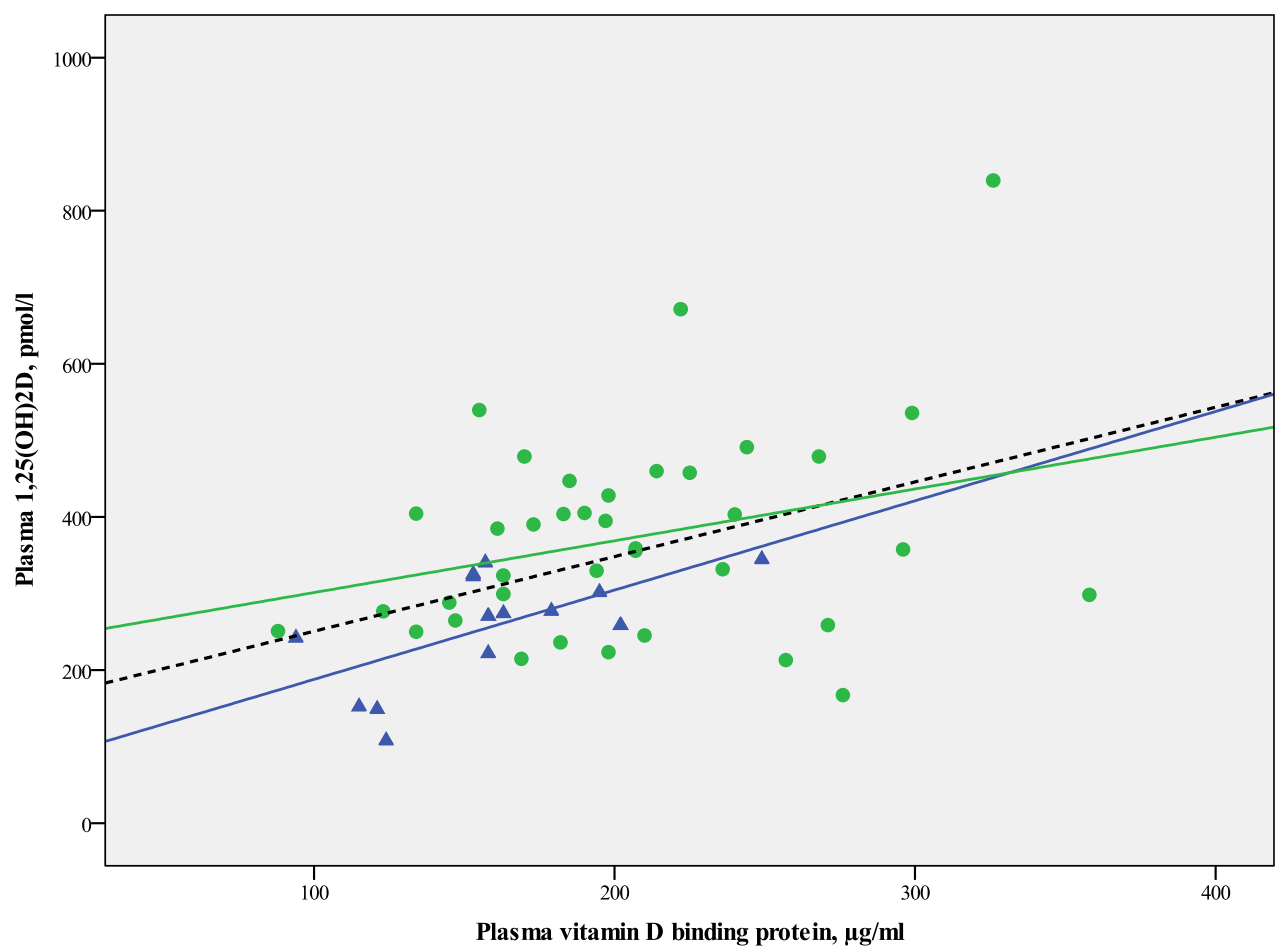

Hormonal contraceptive use

Non hormonal contraceptive users Hormonal contraceptive users

Non hormonal contraceptive user

Hormonal contraceptive users

The group as one

Plasma $1,25(\mathrm{OH})_{2} \mathrm{D}$ was significantly and positively correlated with VDBP concentrations $\left(r_{\mathrm{s}}=0.39, p<0.01\right)$ when data for all women (HC users and non users) were pooled (Figure 1B). 


\subsection{The Effect of Use of Hormonal Contraceptives on $\mathrm{P}-25 \mathrm{OHD}, \mathrm{P}-1,25 \mathrm{OH}_{2} \mathrm{D}$, and $P-V D B P$ Concentrations}

Table 2 details the biochemical indices measured as stratified by whether studied women used HC.

Table 2. Biochemical characteristics as stratified by use of hormonal contraceptives. Data are presented as Median with interquartile (p25; p75) ranges unless otherwise indicated.

\begin{tabular}{|c|c|c|c|c|}
\hline & All, $n=75$ & $\begin{array}{l}\text { Users of hormonal } \\
\text { contraceptive } \\
\text { users } \\
(n=52)\end{array}$ & $\begin{array}{l}\text { Non-users of } \\
\text { hormonal } \\
\text { contraceptives } \\
(n=23)\end{array}$ & $p$ value $^{1}$ \\
\hline Plasma vitamin D binding protein, $\mu \mathrm{g} / \mathrm{mL}$ & $305(251 ; 404)$ & $358(260 ; 432)$ & $271(179 ; 302)$ & $<0.001$ \\
\hline Plasma 25-hydroxyvitamin D, nmol/L & $79(64 ; 104)$ & $84(67 ; 111)$ & $70(47 ; 83)$ & 0.01 \\
\hline Free index 25 -hydroxyvitamin $\mathrm{D}\left(\times 10^{-3}\right)$ & $14(10 ; 19)$ & $14(10 ; 19)$ & $15(10 ; 17)$ & 0.84 \\
\hline Plasma 1,25-dihydroxyvitamin D, pmol/L & $185(156 ; 224)$ & $198(163 ; 241)$ & $158(123 ; 183)$ & 0.01 \\
\hline Free index 1,25 -dihydroxyvitamin $\mathrm{D}\left(\times 10^{-6}\right)$ & $31(26 ; 41)$ & $29(25 ; 41)$ & $36(27 ; 43)$ & 0.10 \\
\hline \multicolumn{5}{|l|}{ Vitamin D status, $N(\%)$} \\
\hline$<50 \mathrm{nmol} / \mathrm{L}$ & $12(16)$ & $6(12)$ & $6(50)$ & \\
\hline $50-75 \mathrm{nmol} / \mathrm{L}$ & $19(25)$ & $12(23)$ & $7(37)$ & $0.15^{2}$ \\
\hline$>75 \mathrm{nmol} / \mathrm{L}$ & $44(59)$ & $34(65)$ & $10(23)$ & \\
\hline Plasma PTH, pmol/L & $3.6(2.9 ; 4.6)$ & $3.3(2.5 ; 4.3)$ & $3.8(3.4 ; 4.6)$ & 0.36 \\
\hline $\begin{array}{l}\text { Plasma calcium total, } \\
\text { albumin adjusted, mmol/L }\end{array}$ & $2.45(2.42 ; 2.52)$ & $2.46(2.43 ; 2.51)$ & $2.45(2.40 ; 2.53)$ & 0.94 \\
\hline Plasma phosphate, $\mathrm{mmol} / \mathrm{L}$ & $1.00(0.93 ; 1.12)$ & $0.97(0.89 ; 1.09)$ & $1.03(0.95 ; 1.21)$ & 0.05 \\
\hline Plasma creatinine, $\mu \mathrm{mol} / \mathrm{L}$ & $64(57 ; 72)$ & $65(57 ; 73)$ & $61(58 ; 69)$ & 0.22 \\
\hline Plasma calcitonin, $\mathrm{pmol} / \mathrm{L}$ & $10(9 ; 12)$ & $10(9 ; 12)$ & $9(8 ; 11)$ & 0.21 \\
\hline $\begin{array}{l}\text { Plasma bone specific } \\
\text { alkaline phosphatase, } \mathrm{U} / \mathrm{L}\end{array}$ & $17.9(14.8 ; 23.0)$ & $16.5(14.6 ; 21.0)$ & $21.1(14.8 ; 23.8)$ & 0.22 \\
\hline Plasma osteocalcin, $\mu \mathrm{g} / \mathrm{L}$ & $26.9(19.3 ; 30.9)$ & $25.9(19.0 ; 29.6)$ & $29.6(20.6 ; 39.2)$ & 0.07 \\
\hline Urine $\mathrm{NTx} /$ creatinine ratio $(\mathrm{mmol} / \mathrm{mmol})$ & $42.6(30.9 ; 53.0)$ & $39.3(29.5 ; 50.8)$ & $48.7(38.8 ; 57.8)$ & 0.11 \\
\hline Urine calcium/creatinine-ratio (mmol/mmol) & $0.2(0.1 ; 0.4)$ & $0.2(0.1 ; 0.4)$ & $0.3(0.1 ; 0.4)$ & 0.52 \\
\hline
\end{tabular}

${ }^{1}$ Independent-Samples Mann-Whitney U Test; ${ }^{2}$ Chi-Square Tests.

Compared with the non-users, $\mathrm{HC}$ users has a significantly higher plasma concentrations of 25OHD, 1,25(OH) $)_{2} \mathrm{D}$, and VDBP $(p<0.01)$. The median plasma concentrations of 25OHD, $1,25(\mathrm{OH})_{2} \mathrm{D}$, and VDBP were respectively $16 \%, 13 \%$, and $25 \%$, higher in users compared to non-users of HC. However, FI-25OHD and FI-1,25(OH) 2 D did not differ between groups.

Adjustment for between group differences in body weight did not change results.

The prevalence of a $25 \mathrm{OHD}$ concentration below $50 \mathrm{nmol} / \mathrm{L}$ was equal between groups, whereas there were three times as many users with a $25 \mathrm{OHD}$ concentration above $75.1 \mathrm{nmol} / \mathrm{L}$ as non-users of HC (Table 2).

The correlation between the plasma concentration of $25 \mathrm{OHD}$ and $1,25(\mathrm{OH})_{2} \mathrm{D}$ was near significant in both users of $\mathrm{HC}\left(r_{\mathrm{s}}=0.31, p=0.06\right)$ and in non-users of $\mathrm{HC}(r=0.49, p=0.07)$.

However, 25OHD and VDBP concentrations were not significantly correlated when groups were analyzed separately (in HC users: $r_{\mathrm{s}}=0.15, p=0.29$ and in non-users: $r_{\mathrm{s}}=0.29, p=0.18$ ). Plasma 
$1,25(\mathrm{OH})_{2} \mathrm{D}$ tended to be positively correlated with VDBP in non-users of $\mathrm{HC}\left(r_{\mathrm{s}}=0.52, p=0.06\right)$, but not in HC users $\left(r_{\mathrm{s}}=0.21, p=0.21\right)$ (Figure 1B).

\subsection{The Effect of Use of Hormonal Contraceptives on Calcium Homeostasis and Bone Turnover}

As shown in Table 2, plasma concentrations of phosphate and osteocalcin were borderline significant lower in users-compared with non-users of HC; whereas no other measured indices differed between groups.

\section{Discussion}

We have studied a group of healthy young Danish women among whom 52 used HC and 23 did not. Our analyses showed significantly higher plasma concentrations of $25 \mathrm{OHD}, 1,25(\mathrm{OH})_{2} \mathrm{D}$ and VDBP in users compared with non-users of $\mathrm{HC}, \mathrm{FI}-25 \mathrm{OHD}$ and $\mathrm{FI}-1,25 \mathrm{OH}_{2} \mathrm{D}$ were however not different between groups.

Our findings of increased VDBP concentrations in users of $\mathrm{HC}$ agrees with the findings in postmenopausal women receiving postmenopausal hormone substitution. In an earlier study from our group, initiation of postmenopausal oestrogen therapy caused a significant $8 \%$ increase in VDBP concentrations [19]. Similar results have been reported in pregnancy, during which an increase in VDBP concentration is observed [10,18].

Plasma $1,25(\mathrm{OH})_{2} \mathrm{D}$ is known to suppress the secretion of PTH, stimulate the synthesis of osteocalcin and enhance intestinal absorption of calcium and phosphate [27,28]. The latter may be reflected in an increase renal excretion of these minerals [27]. Despite a significant increase in plasma $1,25(\mathrm{OH})_{2} \mathrm{D}$ our data did not show any significant effect of $\mathrm{HC}$ on indices of calcium and phosphate homeostasis or bone metabolism. These findings may support the notion of the free hormone hypothesis, i.e., that only the free fraction of the hormone has biological effects [29].

We assume based on our results and previous reports $[5,10,15,18,19]$ that the estrogen component of HC may increase VDBP synthesis or decrease its catabolism. The concomitant increase in the total plasma $1,25(\mathrm{OH})_{2} \mathrm{D}$ concentration may mirror a compensatory adjustment to maintain an unaltered concentration of the free fraction $[10,16,18]$.

VDBP binding protects vitamin D metabolites from hydroxylase-mediated catabolism; an increase in VDBP may therefore reduce further metabolism of vitamin D metabolites, increasing their half-life. An alternative explanation is that, in parallel with the up regulation of the $1,25(\mathrm{OH})_{2} \mathrm{D}$ concentration, the total 25OHD concentration is unregulated via unknown mechanisms, to maintain the free concentration of $25 \mathrm{OHD}$, available to tissues. This may potentially explain the higher plasma concentration of the largely unregulated plasma concentration of 25OHD in HC users, however, this needs further investigation.

An important limitation of our study is the relative small sample size and the fact that women were healthy and all had plasma 25OHD concentrations over $25 \mathrm{nmol} / \mathrm{L}$. This may have limited our ability to detect further potential effects of $\mathrm{HC}$ on calcium homeostasis and bone metabolism through variations in VDBP, 25OHD, and $1,25(\mathrm{OH})_{2} \mathrm{D}$ in vitamin D deficiency $(25 \mathrm{OHD}<25 \mathrm{nmol} / \mathrm{L})$. Further studies should therefore aim to investigate effects of $\mathrm{HC}$ in women with vitamin $\mathrm{D}$ deficiency. 
Moreover, investigations in larger groups are needed to assess the effects of HC on vitamin D metabolites and its effect on muscle and bone, as well as other health outcomes.

\section{Conclusions}

In conclusion, use of $\mathrm{HC}$ is associated with an elevated plasma concentration of VDBP and concomitant higher plasma $25 \mathrm{OHD}$ and $1,25(\mathrm{OH})_{2} \mathrm{D}$. The free-indices of these vitamin $\mathrm{D}$ metabolites are however similar to non-users of HC. The point of emphasis: the use of HC should be considered in the interpretation of $25 \mathrm{OHD}$ and $1,25(\mathrm{OH})_{2} \mathrm{D}$ vitamin $\mathrm{D}$ concentrations in women. Further studies should aim to clarify whether also in women with a low vitamin D supply, an HC induced increase in VDBP is accompanied by an increase in plasma 25OHD to maintain the free 25OHD level. Further research is also required to assess whether the free 25OHD index is a better marker of 25OHD tissue availability and has a higher correlation with indices of calcium homeostasis and bone metabolism than total 25OHD levels.

\section{Acknowledgements}

We are grateful for the financial support provided to the project from: The Danish Agency for Science, Technology and Innovation, The Aarhus University Research Foundation, AP Moeller Foundation for the Advancement of Medical Science, Svend Fældings Humanitære Fond, The Lundbeck Foundation, Aarhus University Fellowship, and Helga and Peter Kornings Foundation. Inez Schoenmakers and Shailja Nigdikar are supported through the core programme of the Nutrition and Bone Research group at MRC Human Nutrition Research funded by UK MRC (grant code U105960371).

\section{Conflicts of Interest}

The authors are not aware of any affiliations, memberships, funding, or financial holdings that might be perceived as affecting the objectivity of this study.

\section{References}

1. Holick, M.F. Vitamin D status: Measurement, interpretation, and clinical application. Ann. Epidemiol. 2009, 19, 73-78.

2. Mosekilde, L. Vitamin D and the elderly. Clin. Endocrinol. 2005, 62, 265-281.

3. Holick, M.F. Resurrection of vitamin D deficiency and rickets. J. Clin. Investig. 2006, 116, 2062-2072.

4. Hewison, M.; Burke, F.; Evans, K.N.; Lammas, D.A.; Sansom, D.M.; Liu, P.; Modlin, R.L.; Adams, J.S. Extra-renal 25-hydroxyvitamin D3-1alpha-hydroxylase in human health and disease. J. Steroid Biochem. Mol. Biol. 2007, 103, 316-321.

5. Bikle, D.D.; Gee, E.; Halloran, B.; Kowalski, M.A.; Ryzen, E.; Haddad, J.G. Assessment of the free fraction of 25-hydroxyvitamin $\mathrm{D}$ in serum and its regulation by albumin and the vitamin D-binding protein. J. Clin. Endocrinol. Metab. 1986, 63, 954-959. 
6. Bikle, D.D.; Siiteri, P.K.; Ryzen, E.; Haddad, J.G. Serum protein binding of 1,25-dihydroxyvitamin D: A reevaluation by direct measurement of free metabolite levels. J. Clin. Endocrinol. Metab. 1985, 61, 969-975.

7. Holick, M.F.; Chen, T.C. Vitamin D deficiency: A worldwide problem with health consequences. Am. J. Clin. Nutr. 2008, 87, 1080S-1086S.

8. Chan, J.; Jaceldo-Siegl, K.; Fraser, G.E. Determinants of serum 25 hydroxyvitamin D levels in a nationwide cohort of blacks and non-Hispanic whites. Cancer Causes Control 2010, 21, 501-511.

9. Nesby-O’Dell, S.; Scanlon, K.S.; Cogswell, M.E.; Gillespie, C.; Hollis, B.W.; Looker, A.C.; Allen, C.; Doughertly, C.; Gunter, E.W.; Bowman, B.A. Hypovitaminosis D prevalence and determinants among African American and white women of reproductive age: Third National Health and Nutrition Examination Survey, 1988-1994. Am. J. Clin. Nutr. 2002, 76, 187-192.

10. Bouillon, R.; van Assche, F.A.; van Baelen, H.; Heyns, W.; de Moor, P. Influence of the vitamin D-binding protein on the serum concentration of 1,25-dihydroxyvitamin D3. Significance of the free 1,25-dihydroxyvitamin D3 concentration. J. Clin. Investig. 1981, 67, 589-596.

11. Haddad, J.G., Jr.; Walgate, J. Radioimmunoassay of the binding protein for vitamin D and its metabolites in human serum: Concentrations in normal subjects and patients with disorders of mineral homeostasis. J. Clin. Investig. 1976, 58, 1217-1222.

12. Møller, U.; Streym, S.; Heickendorff, L.; Mosekilde, L.; Rejnmark, L. Effects of 25OHD concentrations on chances of pregnancy and pregnancy outcomes. A cohort study in healthy Danish women. Eur. J. Clin. Nutr. 2012, 66, 862-868.

13. Cross, N.A.; Hillman, L.S.; Allen, S.H.; Krause, G.F. Changes in bone mineral density and markers of bone remodeling during lactation and postweaning in women consuming high amounts of calcium. J. Bone Miner. Res. 1995, 10, 1312-1320.

14. Ritchie, L.D.; Fung, E.B.; Halloran, B.P.; Turnlund, J.R.; van Loan, M.D.; Cann, C.E.; King, J.C. A longitudinal study of calcium homeostasis during human pregnancy and lactation and after resumption of menses. Am. J. Clin. Nutr. 1998, 67, 693-701.

15. Aarskog, D.; Aksnes, L.; Markestad, T.; Rodland, O. Effect of estrogen on vitamin D metabolism in tall girls. J. Clin. Endocrinol. Metab. 1983, 57, 1155-1158.

16. Harris, S.S.; Dawson-Hughes, B. The association of oral contraceptive use with plasma 25-hydroxyvitamin D levels. J. Am. Coll. Nutr. 1998, 17, 282-284.

17. Gagnon, C.; Baillargeon, J.P.; Desmarais, G.; Fink, G.D. Prevalence and predictors of vitamin D insufficiency in women of reproductive age living in northern latitude. Eur. J. Endocrinol. 2010, $163,819-824$.

18. Van Hoof, H.J.; de Sevaux, R.G.; van Baelen, H.; Swinkels, L.M.; Klipping, C.; Ross, H.A.; Sweep, C.G. Relationship between free and total 1,25-dihydroxyvitamin D in conditions of modified binding. Eur. J. Endocrinol. 2001, 144, 391-396.

19. Rejnmark, L.; Lauridsen, A.L.; Brot, C.; Vestergaard, P.; Heickendorff, L.; Nexo, E.; Mosekilde, L. Vitamin D and its binding protein Gc: Long-term variability in peri- and postmenopausal women with and without hormone replacement therapy. Scand. J. Clin. Lab. Investig. 2006, 66, 227-238. 
20. Gravholt, C.H.; Leth-Larsen, R.; Lauridsen, A.L.; Thiel, S.; Hansen, T.K.; Holmskov, U.; Naeraa, R.W.; Christiansen, J.S. The effects of GH and hormone replacement therapy on serum concentrations of mannan-binding lectin, surfactant protein D and vitamin D binding protein in Turner syndrome. Eur. J. Endocrinol. 2004, 150, 355-362.

21. Moller, U.K.; við Streym, S.; Mosekilde, L.; Rejnmark, L. Changes in bone mineral density and body composition during pregnancy and postpartum. A controlled cohort study. Osteoporos. Int. 2012, 23, 1213-1223.

22. Hermann, A.P.; Thomsen, J.; Vestergaard, P.; Mosekilde, L.; Charles, P. Assessment of kalcium intake. A quick method comparerd to a 7 days food diary. Calcif. Tissue Int. 1999, 64, S82.

23. Maunsell, Z.; Wright, D.J.; Rainbow, S.J. Routine isotope-dilution liquid chromatography-tandem mass spectrometry assay for simultaneous measurement of the 25-hydroxy metabolites of vitamins D2 and D3. Clin. Chem. 2005, 51, 1683-1690.

24. Hojskov, C.S.; Heickendorff, L.; Moller, H.J. High-throughput liquid-liquid extraction and LCMSMS assay for determination of circulating 25(OH) vitamin D3 and D2 in the routine clinical laboratory. Clin. Chim. Acta 2010, 411, 114-116.

25. Schifter, S. A new highly sensitive radioimmunoassay for human calcitonin useful for physiological studies. Clin. Chim. Acta 1993, 215, 99-109.

26. Mosekilde, L. Vitamin D requirement and setting recommendation levels: Long-term perspectives. Nutr. Rev. 2008, 66, S170-S177.

27. Favus, M. Primer on the Metabolic Bone Diseases and Disorders of Mineral Metabolism, 6th ed.; Bikle, D.D., Christakos, S., Goldring, S.R., Guise, T.H., Holick, M.F., Jan de Beur, S., Kaplan, F.S., Kleerekoper, M., Langman, C.B., Lian, J.B., et al., Eds.; American Society for Bone and Mineral Research: Washington, DC, USA, 2006; pp. 50-132.

28. Henry, H.L.; Norman, A.W. Vitamin D: Metabolism and biological actions. Annu. Rev. Nutr. 1984, 4, 493-520.

29. Mendel, C.M. The free hormone hypothesis: A physiologically based mathematical model. Endocr. Rev. 1989, 10, 232-274.

(C) 2013 by the authors; licensee MDPI, Basel, Switzerland. This article is an open access article distributed under the terms and conditions of the Creative Commons Attribution license (http://creativecommons.org/Licenses/by/3.0/). 